\title{
Population structure of a parasitic plant and its perennial host
}

\author{
P Mutikainen ${ }^{1}$ and T Koskela ${ }^{2}$ \\ ${ }^{1}$ Department of Biology, University of Oulu, PO Box 3000, FIN-90014 University of Oulu, Finland; ${ }^{2}$ Department of Biological and \\ Environmental Science, University of Jyväskylä, PO Box 35, FIN-40351 Jyväskylä, Finland
}

\begin{abstract}
Characterization of host and parasite population genetic structure and estimation of gene flow among populations are essential for the understanding of parasite local adaptation and coevolutionary interactions between hosts and parasites. We examined two aspects of population structure in a parasitic plant, the greater dodder (Cuscuta europaea) and its host plant, the stinging nettle (Urtica dioica), using allozyme data from 12 host and eight parasite populations. First, we examined whether hosts exposed to parasitism in the past contain higher levels of genetic variation. Second, we examined whether host and parasite populations differ in terms of population structure and if their population structures are correlated. There was no evidence that host populations differed in terms of gene diversity or heterozygosity
\end{abstract}

according to their history of parasitism. Host populations were genetically more differentiated $\left(F_{\mathrm{ST}}=0.032\right)$ than parasite populations $\left(F_{\mathrm{ST}}=0.009\right)$. Based on these $F_{\mathrm{ST}}$ values, gene flow was high for both host and parasite. Such high levels of gene flow could counteract selection for local adaptation of the parasite. We found no significant correlation between geographic and genetic distance (estimated as pairwise $F_{\mathrm{ST}}$ ), either for the host or for the parasite. Furthermore, host and parasite genetic distance matrices were uncorrelated, suggesting that sites with genetically similar host populations are unlikely to have genetically similar parasite populations.

Heredity (2002) 89, 318-324. doi:10.1038/sj.hdy.6800142

Keywords: host-parasite interaction; genetic structure; coevolution; gene flow; Cuscuta europaea; Urtica dioica

\section{Introduction}

Host-parasite coevolution depends on genetic variation, population structure and gene flow of the interacting species (Price, 1980; Thompson, 1994). According to Price (1980), parasite populations will tend to be more strongly structured than their hosts, with low rates of gene flow, leading to local adaptation and host-race formation. Relative migration rates of hosts and parasites are considered important in shaping the outcome of the coevolutionary interaction (Gandon et al, 1996; Lively, 1999) since migration affects the spread of resistant and susceptible host genotypes as well as that of virulent and avirulent parasite genotypes. Theoretically, the ability of parasites to adapt to their local hosts depends significantly on the relative migration rates of the host and the parasite. Local adaptation is expected when the parasite has a higher migration rate than the host and when the parasite is highly virulent (Gandon et al, 1996; Lively, 1999).

Nonetheless, empirical tests of these predictions are rare (Mulvey et al, 1991; Michalakis et al, 1994; Nadler, 1995; Dybdahl and Lively, 1996; Davies et al, 1999; Delmotte et al, 1999) and sometimes in contradiction. For example, populations of freshwater snails can be more strongly structured than those of their parasitic trematodes (Dybdahl and Lively, 1996; Davies et al, 1999).

Correspondence: P Mutikainen, Department of Biology, University of Oulu, PO Box 3000, FIN-90014 University of Oulu, Finland. E-mail: pia.mutikainen@oulu.fi

Received 15 October 2001; accepted 14 June 2002
Mulvey et al (1991) observed significant population differentiation for a fluke as well as for its host, the whitetailed deer. In contrast, three of the previous cases studied show the opposite pattern. Populations of weedy plants can be less strongly differentiated than those of their seed-eating weevils or fungal pathogens (Michalakis et al, 1994; Delmotte et al, 1999). Furthermore, a brood parasitic cuckoo showed stronger population structure than its host, the magpie (Martinez et al, 1999). In the freshwater snail-trematode interaction the parasites are locally adapted to their hosts (Lively, 1989) and also have higher migration rates than their hosts (Dybdahl and Lively, 1996). In the dioecious plant-fungal pathogen interaction the parasites are not locally adapted to their hosts (Kaltz et al, 1999) and show less gene flow than their hosts (Delmotte et al, 1999).

We have previously observed local adaptation of the parasitic plant, the greater dodder (Cuscuta europaea) to its host, the stinging nettle (Urtica dioica) in terms of infectivity, although the degree of local adaptation differed among populations (Koskela et al, 2000). Thus, in this case, one might expect that the parasitic plant has a higher migration rate than its host plant. In this study, we tested this prediction. We examined genetic variation and population structure of the parasitic plant (C. europaea) and its host (U. dioica) using allozyme data from 12 host and eight parasite populations. We addressed two issues. First, by comparing populations that differ in their histories of parasitism we examined whether parasitism is associated with higher level of genetic variation in the host. Host plants from populations free of parasit- 
ism allocate more of their vegetative biomass to asexual reproduction than host plants from populations with a history of parasitism (Koskela, 2002). This difference may indicate that parasitism has favored resource allocation to sexual reproduction, which promotes high levels of genetic polymorphism (Jaenike, 1978; Hamilton, 1980; Bell, 1982). In this study, we examined whether this difference is reflected in the level of neutral genetic variation measured using allozymes. Using this data, we were also able to characterize the breeding systems of the host and the parasite. Second, we examined whether host and parasite populations differ in terms of population differentiation, and whether their population structures are correlated. A significant correlation between the genetic population structures of host and parasite could indicate that the rates of dispersal are similar or that parasites respond to the local selection imposed by host resistance and hosts in turn respond to selection for resistance. In the latter case, the neutral markers assayed would be linked to the loci under selection. Since we have previously observed local adaptation in the present study system (Koskela et al, 2000), local selection seems to occur.

\section{Materials and methods}

\section{Study species and populations}

The stinging nettle, $U$. dioica L. (Urticaceae), is a windpollinated perennial species that is common in nutrientrich habitats in most of southern Finland. It is dioecious and therefore obligately outcrossing. Urtica dioica genets spread by seed and pollen dispersal, and ramets spread by rhizomes. The greater dodder, C. europaea L. (Cuscutaceae) is an annual holoparasitic vine that mostly lacks chlorophyll (Machado and Zetsche, 1990; Parker and Riches, 1993), and is thus completely dependent on its host for resources. Holoparasitic plants extract water, nutrients, and carbon predominantly from the phloem of their hosts via haustorial connections (Kuijt, 1969; Press et al, 1990; Parker and Riches, 1993). Although Cuscuta species are usually generalists in their host choice (eg, Parker and Riches, 1993; Musselman and Press, 1995), the main host of $C$. europaea in the populations studied here was $U$. dioica. Cuscuta europaea is pollinated by insects (Kuijt, 1969).

We collected samples for electrophoresis in $12 U$. dioica populations in southern Finland (Figure 1). Eight of the populations sampled were parasitised by C. europaea (populations 1-7, 11; Figure 1), whereas in four of the populations the parasitic plant was absent (populations 8-10, 12; Figure 1). Regardless of their parasitism status, the host populations were similar in terms of habitat type, vegetation and soil nutrient levels (Koskela, 2002). Cuscuta europaea was abundant in the parasitised populations, and present in $87.5 \%$ of plots (10 plots, each 0.25 $\mathrm{m}^{2}$ in area) in which $U$. dioica occurred (Koskela, 2002). Geographic distances among the study populations ranged from 0.5 to $166 \mathrm{~km}$ (Figure 1). Distances between nonparasitised and parasitised populations were at least $800 \mathrm{~m}$. The eight parasite populations sampled occurred in the same sites as the eight parasitised host populations (populations 1-7, 11; Figure 1).

\section{Sampling and electrophoresis}

In summer 1999, we collected seeds from 20 to 30 host individuals from each of the 12 populations. The seeds were germinated in January 2000 in a greenhouse, and a fresh leaf sample (about $1 \mathrm{~cm}^{2}$ in leaf area) from one seedling per family was used for the allozyme analysis. In July 2000, we collected samples from 20 to 40 parasitic plants from each of the eight infected populations. The samples (about $2 \mathrm{~cm}$ in stem length) were snap-frozen for electrophoresis and reserved at $-81^{\circ} \mathrm{C}$.

We performed cellulose acetate electrophoresis (Helena Laboratories, Beaumont, TX, USA) on both host and parasite using the stains and buffer recipes described in Richardson et al (1986) and Hebert and Beaton (1989). For both the host and parasite, 10 enzymes were screened. For the host plant, four loci were reliably resolved and turned out to be polymorphic: GPI (glucose-6-phosphate isomerase, E.C. 5.3.1.9), 6-PGD (6-phosphogluconate dehydrogenase, E.C. 1.1.1.44), PGM-1 and PGM-2 (two isozymes of phosphoglycerate mutase, E.C. 2.5.7.3). For the parasitic plant, only PGM (phosphoglycerate mutase, E.C. 2.5.7.3) and DIA (diaphorase, E.C. 1.6.99.-) were reliably resolved and polymorphic.

\section{Data analysis}

Allele frequencies and gene diversities within populations were estimated according to Nei (1987) using FSTAT v. 2.8 (Goudet, 1999). Within-population and overall heterozygote deficiency $\left(F_{\mathrm{IS}}\right)$ were estimated using FSTAT (Goudet, 1999). Standard deviations for within population $F_{\text {IS }}$ values were obtained by bootstrapping over loci using MATLAB ${ }^{\mathrm{TM}}$ routines written by J Jokela. To test for a significant overall deviation from HardyWeinberg proportions $\left(F_{\text {IS }}\right)$ alleles were randomized over the whole dataset (Goudet, 1999).

To examine differentiation among the eight infected host populations and the parasite populations, pairwise and overall $F_{\mathrm{ST}}$ values were calculated using FSTAT (Goudet, 1999). For the overall $F_{\mathrm{ST}}$, genotypes were randomized among samples, and the log-likelihood G-statistic was used to test for a significant deviation of $F_{\mathrm{ST}}$ from zero (Goudet et al, 1996). Gene flow among the populations was inferred from the $F_{\mathrm{ST}}$ values (Whitlock and McCauley, 1999). To test for isolation by distance for the host and parasite, we compared the matrices of pairwise $F_{\mathrm{ST}}$ (ie, genetic distances) and pairwise geographic distances using Mantel test (Mantel, 1967). For these analyses, the pairwise $F_{\mathrm{ST}}$ values were transformed as $F_{\mathrm{ST}} /\left(1-F_{\mathrm{ST}}\right)$ (Rousset and Raymond, 1997) and the geographic distances were log-transformed. To test if the host and parasite had correlated population structures we compared the matrix of host pairwise $F_{\mathrm{ST}}$ to the matrix of parasite pairwise $F_{\mathrm{ST}}$ using a Mantel test.

\section{Results}

\section{General}

For all of the 12 host populations, all four loci analysed were polymorphic; the average number of alleles per locus varied between three and six (Table 1). For the parasite, the average number of alleles varied between two and three in the two polymorphic loci analysed (Table 2). Overall, the parasite had a higher level of homozygosity than the host, although both host and 


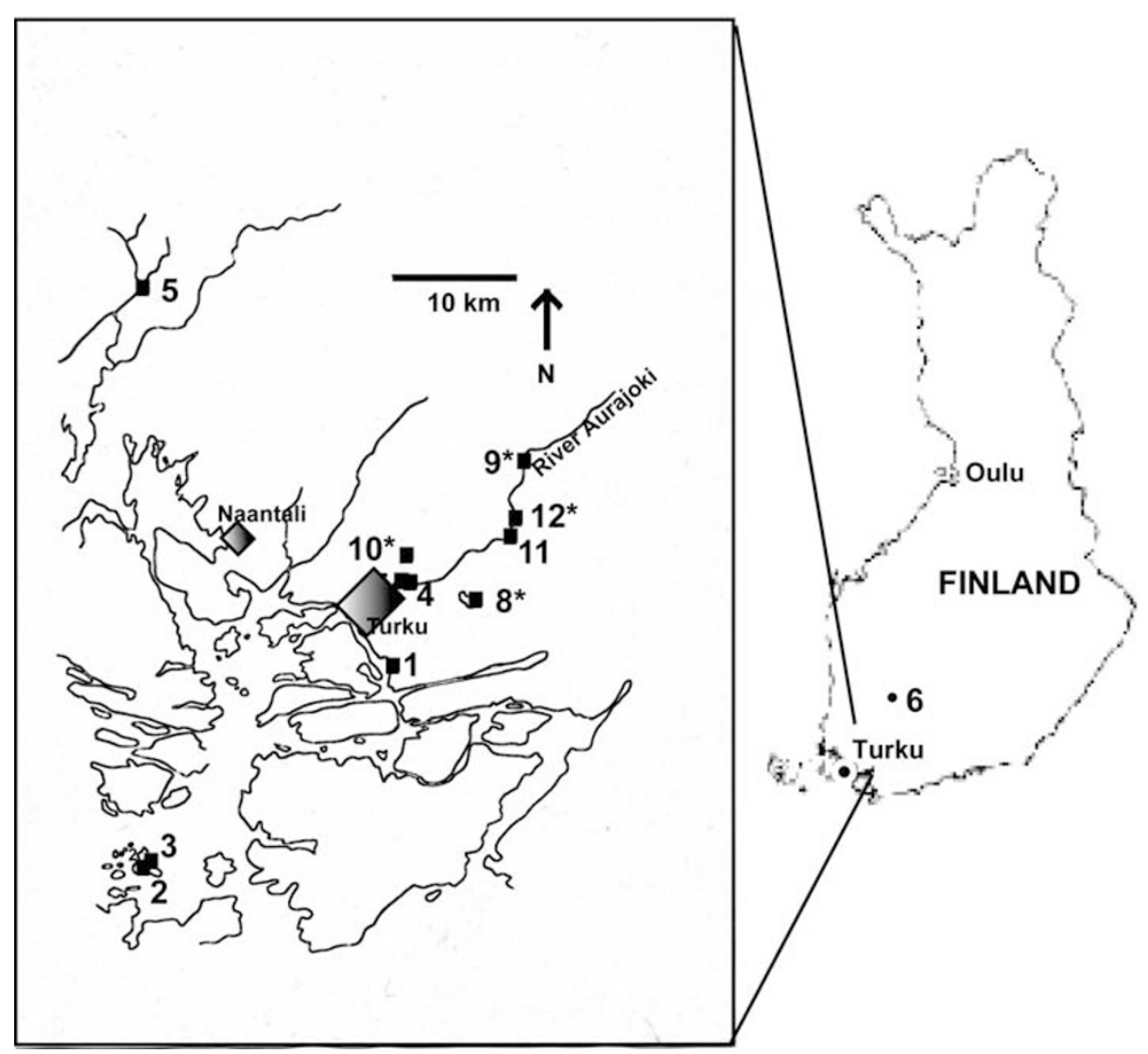

Figure 1 A map showing the locations of the 12 study sites. Sites marked with an asterisk $\left(^{*}\right)$ are host (Urtica dioica) populations that have not been parasitised by the parasitic plant Cuscuta europaea.

parasite had significant heterozygote deficiency (host: $F_{\text {IS }}$ $=0.117$, parasite: $F_{\mathrm{IS}}=0.444$ ) (Table 3 ). Differences in inbreeding coefficient were larger among host populations than among parasite populations. Three of the host populations actually had an excess of heterozygotes (Table 3).

\section{Comparison of non-parasitised and parasitised host populations}

The non-parasitised and parasitised populations did not differ from each other in terms of gene diversity (mean (SD) non-parasitised: $\mathrm{H}_{\mathrm{E}}=0.480(0.018)$, parasitised: $\mathrm{H}_{\mathrm{E}}$ $=0.520(0.021) ; \mathrm{t}=1.230$, d.f. $=10, P=0.247)$ or in terms of inbreeding coefficient (non-parasitised: $F_{\mathrm{IS}}=0.017$ (0.052), parasitised: $F_{\mathrm{IS}}=0.087(0.053) ; \mathrm{t}=0.836$, d.f. $=10, P=$ 0.423).

\section{Population differentiation}

Since we wanted to compare host and parasite population differentiation, we included only the eight infected host populations in the following analyses. Host populations were more genetically differentiated $\left(F_{\mathrm{ST}}=0.032\right)$ than parasite populations $\left(F_{\mathrm{ST}}=0.009\right)$. Both $F_{\mathrm{ST}}$ values differed significantly from zero (log-likelihood $G, P<$ 0.05). We found no significant correlation between geographic distance and pairwise $F_{\mathrm{ST}}$ either for the host (Mantel test: $r=-0.114, P>0.351$; Figure 2a) or for the parasite (Mantel test: $r=0.199, P>0.810$; Figure 2b). Lastly, host and parasite pairwise $F_{\mathrm{ST}}$ matrices were not significantly correlated (Mantel test: $r=-0.316, P>0.114$; Figure 2c).

\section{Discussion}

Our results are consistent with the results of a few previous studies on host and parasite population genetic structures in that we found stronger differentiation for the host plant than for the parasite. The low $F_{\mathrm{ST}}$ value observed for the parasite could indicate either higher gene flow or lower genetic drift in the parasite populations than in the host populations. Since not all host individuals are infected, the parasite populations are typically smaller, and are also likely to be younger than the host populations. Thus, one would expect more genetic drift and stronger population differentiation in the parasite (Whitlock and McCauley, 1990; Giles and Goudet, 1997). High gene flow is thus likely to explain the low differentiation observed for the parasite.

Interestingly, the results of two previous cases in which both local adaptation and population structure were studied in the same host-parasite system support the theoretical models that emphasize the importance of the relative migration of host and parasite (Gandon et al, 1996; Lively, 1999). Here, inferred gene flow in the parasite was higher than that in the host, theoretically consistent with local adaptation. Nonetheless, parasite gene flow as high as observed here may reintroduce parasite genetic diversity and prevent local adaptation and formation of local host races. Furthermore, differences in the level of local adaptation become more likely, and local adaptation more difficult to detect, as the parasite migration rate increases (Lively, 1999). Thus, the local adaptation previously observed in this study system (Koskela et al, 2000) 
Table 1 Gene diversity $\left(\mathrm{H}_{e}\right)$ and allele frequencies for four allozyme loci in 12 populations of the host plant (Urtica dioica). Four of the populations were not parasitised (marked with an asterisk *)

\begin{tabular}{|c|c|c|c|c|c|c|c|c|c|c|c|c|c|}
\hline Population & 1 & 2 & 3 & 4 & 5 & 6 & 7 & $8^{*}$ & $9^{*}$ & $10^{*}$ & 11 & $12^{*}$ & All \\
\hline \multicolumn{14}{|l|}{ GPI } \\
\hline$n$ & 24 & 21 & 19 & 26 & 21 & 24 & 22 & 24 & 22 & 25 & 17 & 18 & \\
\hline 1 & - & - & 0.026 & 0.019 & 0.024 & - & - & - & - & 0.020 & - & - & 0.008 \\
\hline 2 & 0.063 & 0.048 & 0.026 & 0.115 & 0.119 & 0.042 & 0.250 & 0.188 & 0.182 & 0.080 & 0.059 & 0.083 & 0.106 \\
\hline 3 & 0.479 & 0.333 & 0.316 & 0.346 & 0.452 & 0.479 & 0.477 & 0.417 & 0.227 & 0.220 & 0.294 & 0.444 & 0.375 \\
\hline 4 & 0.354 & 0.524 & 0.500 & 0.481 & 0.310 & 0.333 & 0.205 & 0.354 & 0.273 & 0.440 & 0.500 & 0.417 & 0.388 \\
\hline 5 & 0.104 & 0.095 & 0.132 & 0.038 & 0.095 & 0.104 & 0.068 & 0.042 & 0.250 & 0.220 & 0.059 & 0.056 & 0.106 \\
\hline 6 & - & - & - & - & - & 0.042 & - & - & 0.068 & 0.020 & 0.088 & - & 0.017 \\
\hline$H_{e}$ & 0.638 & 0.614 & 0.645 & 0.643 & 0.692 & 0.661 & 0.677 & 0.676 & 0.789 & 0.714 & 0.671 & $\begin{array}{c}0.629 \\
\mathrm{H}_{e} \mathrm{SD}=\end{array}$ & $\begin{array}{l}0.671 \\
0.014\end{array}$ \\
\hline \multicolumn{14}{|l|}{$P G D$} \\
\hline$n$ & 26 & 21 & 20 & 27 & 21 & 23 & 22 & 22 & 22 & 25 & 17 & 19 & \\
\hline 1 & 0.096 & 0.071 & 0.075 & 0.093 & 0.095 & 0.196 & 0.114 & 0.045 & 0.091 & 0.040 & 0.059 & 0.105 & 0.091 \\
\hline 2 & 0.788 & 0.667 & 0.775 & 0.741 & 0.643 & 0.696 & 0.864 & 0.932 & 0.864 & 0.840 & 0.912 & 0.895 & 0.798 \\
\hline 3 & 0.115 & 0.262 & 0.150 & 0.167 & 0.262 & 0.109 & 0.023 & 0.023 & 0.045 & 0.120 & 0.029 & - & 0.111 \\
\hline \multirow[t]{2}{*}{$\mathrm{H}_{e}$} & 0.365 & 0.501 & 0.384 & 0.427 & 0.529 & 0.477 & 0.246 & 0.132 & 0.249 & 0.287 & 0.169 & 0.193 & 0.330 \\
\hline & & & & & & & & & & & & $\mathrm{H}_{e} \mathrm{SD}=$ & 0.040 \\
\hline \multicolumn{14}{|l|}{$P G M-1$} \\
\hline$n$ & 24 & 17 & 20 & 25 & 18 & 20 & 22 & 23 & 15 & 24 & 17 & 17 & \\
\hline 1 & - & - & - & 0.020 & - & - & 0.023 & 0.065 & - & - & - & 0.059 & 0.014 \\
\hline 2 & 0.625 & 0.265 & 0.425 & 0.340 & 0.333 & 0.500 & 0.318 & 0.304 & 0.367 & 0.229 & 0.324 & 0.382 & 0.370 \\
\hline 3 & 0.125 & 0.441 & 0.350 & 0.500 & 0.472 & 0.425 & 0.500 & 0.413 & 0.467 & 0.563 & 0.441 & 0.382 & 0.421 \\
\hline 4 & 0.250 & 0.206 & 0.225 & 0.140 & 0.139 & 0.075 & 0.136 & 0.152 & 0.167 & 0.167 & 0.147 & 0.147 & 0.163 \\
\hline 5 & - & 0.088 & - & - & 0.056 & - & 0.023 & 0.065 & - & 0.042 & 0.088 & 0.029 & 0.031 \\
\hline \multirow[t]{2}{*}{$H_{e}$} & 0.545 & 0.706 & 0.663 & 0.623 & 0.663 & 0.588 & 0.642 & 0.722 & 0.640 & 0.616 & 0.689 & 0.706 & 0.650 \\
\hline & & & & & & & & & & & & $\mathrm{H}_{e} \mathrm{SD}=$ & 0.015 \\
\hline \multicolumn{14}{|l|}{ PGM-2 } \\
\hline$n$ & 23 & 21 & 19 & 21 & 20 & 24 & 22 & 24 & 19 & 23 & 17 & 16 & \\
\hline 1 & - & - & - & - & - & - & 0.023 & - & 0.079 & - & - & 0.031 & 0.010 \\
\hline 2 & - & 0.381 & 0.158 & 0.095 & 0.300 & 0.042 & 0.227 & 0.021 & 0.079 & 0.109 & 0.206 & 0.094 & 0.139 \\
\hline 3 & 0.848 & 0.405 & 0.684 & 0.786 & 0.550 & 0.750 & 0.750 & 0.792 & 0.763 & 0.696 & 0.735 & 0.844 & 0.717 \\
\hline 4 & 0.152 & 0.214 & 0.158 & 0.119 & 0.150 & 0.208 & - & 0.188 & 0.079 & 0.196 & 0.059 & 0.031 & 0.135 \\
\hline \multirow[t]{2}{*}{$\mathrm{H}_{e}$} & 0.267 & 0.669 & 0.497 & 0.371 & 0.600 & 0.406 & 0.392 & 0.351 & 0.412 & 0.477 & 0.426 & 0.285 & 0.429 \\
\hline & & & & & & & & & & & & $\mathrm{H}_{e} \mathrm{SD}=$ & 0.034 \\
\hline
\end{tabular}

Table 2 Gene diversity $\left(\mathrm{H}_{e}\right)$ and allele frequencies for two allozyme loci in eight populations of the parasitic plant Cuscuta europaea

\begin{tabular}{|c|c|c|c|c|c|c|c|c|c|}
\hline Population & 1 & 2 & 3 & 4 & 5 & 6 & 7 & 11 & All \\
\hline \multicolumn{10}{|l|}{$P G M$} \\
\hline$n$ & 11 & 19 & 24 & 23 & 15 & 14 & 19 & 7 & \\
\hline 1 & 0.045 & - & - & - & - & - & - & 0.071 & 0.008 \\
\hline 2 & 0.364 & 0.500 & 0.313 & 0.478 & 0.300 & 0.464 & 0.395 & 0.643 & 0.417 \\
\hline 3 & 0.591 & 0.500 & 0.688 & 0.522 & 0.700 & 0.536 & 0.605 & 0.286 & 0.576 \\
\hline \multirow[t]{2}{*}{$\mathrm{H}_{e}$} & 0.545 & 0.509 & 0.438 & 0.512 & 0.438 & 0.516 & 0.491 & 0.524 & 0.497 \\
\hline & & & & & & & & $\mathrm{H}_{e} \mathrm{SD}=$ & 0.014 \\
\hline \multicolumn{10}{|l|}{$D I A$} \\
\hline$n$ & 20 & 23 & 33 & 32 & 23 & 20 & 23 & 12 & \\
\hline 1 & 0.200 & 0.022 & 0.061 & 0.203 & - & - & 0.022 & - & 0.073 \\
\hline 2 & 0.550 & 0.609 & 0.606 & 0.531 & 0.543 & 0.800 & 0.609 & 0.500 & 0.594 \\
\hline 3 & 0.250 & 0.370 & 0.333 & 0.266 & 0.457 & 0.200 & 0.370 & 0.500 & 0.333 \\
\hline \multirow[t]{2}{*}{$\mathrm{H}_{e}$} & 0.621 & 0.513 & 0.534 & 0.623 & 0.518 & 0.337 & 0.511 & 0.545 & 0.525 \\
\hline & & & & & & & & $\mathrm{H}_{e} \mathrm{SD}=$ & 0.031 \\
\hline
\end{tabular}

is likely to be a consequence of strong local selection on parasite infectivity and virulence.

Contrary to previous studies (Dybdahl and Lively, 1996; Delmotte et al, 1999), we observed no significant correlation between genetic (estimated as pairwise $F_{\mathrm{ST}}$ ) and geographic distances among the populations either for the host or the parasite. Furthermore, host and para- site genetic structures were uncorrelated, suggesting that sites with genetically similar host populations are unlikely to have genetically similar parasite populations. Similarly, Mulvey et al (1991), who studied white-tailed deer and its fluke, and Michalakis et al (1994), who studied a thistle and a seed-eating weevil, found that the patterns of genetic distances in the hosts were not concord- 
Table 3 Gene diversity $\left(\mathrm{H}_{e}\right), F_{\mathrm{IS}}$ and its standard deviation (SD) for 12 populations of the host plant (Urtica dioica) and for eight populations of the parasitic plant (Cuscuta europaea). Eight of the host populations were from the same sites as the parasite populations; four of the host populations were not parasitised (marked with an asterisk *). Mean values of $\mathrm{H}_{e}$ and the overall $F_{\mathrm{IS}}$ values for the host are based on the eight parasitised population. Both overall $\mathrm{F}_{\mathrm{IS}}$ values (marked with two asterisks ${ }^{* *}$ ) differ significantly from zero

\begin{tabular}{|c|c|c|c|c|c|c|c|}
\hline \multicolumn{2}{|c|}{ Population } & \multicolumn{3}{|c|}{ Host } & \multicolumn{3}{|c|}{ Parasite } \\
\hline & & $H_{e}$ & $F_{I S}$ & $S D$ & $H_{e}$ & $F_{I S}$ & $S D$ \\
\hline 1 & Vaarniemi & 0.444 & 0.068 & 0.189 & 0.556 & 0.461 & 0.186 \\
\hline 2 & Seili & 0.604 & 0.208 & 0.173 & 0.496 & 0.270 & 0.411 \\
\hline 3 & Seili seashore & 0.533 & 0.046 & 0.098 & 0.474 & 0.538 & 0.379 \\
\hline 4 & Halistenkoski & 0.506 & 0.014 & 0.173 & 0.553 & 0.514 & 0.233 \\
\hline 5 & Mynämäki & 0.603 & 0.134 & 0.111 & 0.458 & 0.621 & 0.245 \\
\hline 6 & Tampere & 0.517 & 0.360 & 0.123 & 0.409 & 0.504 & 0.340 \\
\hline 7 & Ylioppilaskylä & 0.480 & -0.138 & 0.037 & 0.485 & 0.359 & 0.219 \\
\hline $8^{*}$ & Kuoviluoto & 0.459 & 0.133 & 0.178 & & & \\
\hline $9^{*}$ & Nautelankoski & 0.509 & -0.031 & 0.074 & & & \\
\hline & Vähäjoki & 0.512 & 0.069 & 0.104 & & & \\
\hline 11 & Lieto & 0.474 & 0.006 & 0.054 & 0.500 & 0.411 & 0.477 \\
\hline $12^{*}$ & Lieto riverbank & 0.442 & -0.103 & 0.137 & & & \\
\hline \multirow{2}{*}{\multicolumn{2}{|c|}{$\begin{array}{l}\text { Mean } \\
\text { SD }\end{array}$}} & 0.520 & \multirow{2}{*}{\multicolumn{2}{|c|}{$0.117^{* *}$}} & 0.491 & $0.444^{* *}$ & \\
\hline & & 0.058 & & & 0.048 & & \\
\hline
\end{tabular}

ant with those of their parasites. Michalakis et al (1994) suggest that this lack of concordance is caused by the ephemerality of the thistle populations that selects for increased migration between the weevil populations. This explanation is unlikely to work in our study system since the host plant is a relatively long-lived perennial and the populations are rather stable. In contrast to the other studies, Dybdahl and Lively (1996) found concordant patterns of genetic distances between a freshwater snail and its trematode parasite. In that case, the concordant population differentiation between the host and the parasite was more likely to be explained by the similar dispersal patterns of the two interacting species than by responses of the host and parasite to the local selection by each other (Dybdahl and Lively, 1996).

Our results may be affected by two additional factors. First, we mostly examined population differentiation over a small geographic scale; the distance among the sites varied from 0.5 to $166 \mathrm{~km}$. Relative population differentiation of the host and parasite might have been different if studied over a larger geographic scale. However, site 6 was more than $130 \mathrm{~km}$ away from all of the other populations and did not significantly differ from the other populations. Second, the use of indirect estimates of gene flow, such as the $F_{\mathrm{ST}}$ values, is not the best possible way to estimate gene flow among populations and must be interpreted with caution (Whitlock and McCauley, 1999). However, even if the assumptions for inferring gene flow from the $F_{\mathrm{ST}}$ values are not likely to be fulfilled in the present study system, they are likely to be violated to the same degree in the host and the parasite.

The difference in the level of heterozygosity between the host and the parasite (ie, $F_{\text {IS }}=0.117$ vs 0.444 ) probably reflects the differences in the mating systems of these two species. The host is dioecious and thus an obligate outcrosser whereas the mating system of the parasite is poorly known. According to our results, the parasite is highly inbreeding. In addition, parasite populations are usually clearly smaller than host populations since only a part of the host individuals is typically infected. These two species also differ in their pollination biology: the host is wind-pollinated whereas the parasite is insectpollinated. In general, animal-pollinated species tend to have less gene flow than wind-pollinated species (Hamrick, 1989; Hamrick and Godt, 1990). In addition to pollen, both species disperse by relatively large seeds (compared with other parasitic plants) that probably do not disperse long distances. Given these facts, and opposite to what we observed, one could actually expect higher population differentiation for the parasite. The levels of migration and population differentiation observed here are similar to, or even higher, than those usually observed for outcrossing, wind-pollinated species (Hamrick, 1989; Hamrick and Godt, 1990).

According to our results, populations of the stinging nettle did not differ in their level of genetic variation according to their history of infection by the parasitic plant. We have previously observed differences between the two types of host populations (previously nonparasitised and previously parasitised) in parasite resistance and tolerance (Koskela et al, 2001) as well as in allocation to asexual reproduction (Koskela, 2002). The results of the present study suggest that if these differences in host traits are adaptations caused by parasite-mediated selection, this is not reflected in the levels of neutral genetic variation estimated using allozymes.

When interpreting our results, one has to keep in mind that we have examined population differentiation in this host-parasite interaction using neutral markers. In general, neutral alleles that are unlinked to selected loci are more likely to become established in the populations, leading to lower allozymic differentiation compared to differentiation measured in terms of adaptive phenotypic traits (eg, Lande and Barrowclough, 1987; Goodnight, 1988; Podolsky and Holtsford, 1995). However, the outcome of a coevolutionary interaction depends on the population structure of loci coding for infectivity and virulence of the parasite, and for resistance and tolerance of the host. Since we have previously observed divergence in host resistance and tolerance that is at least partly genetically determined (Koskela et al, 2001), it seems that local selection for parasite infectivity, viru- 


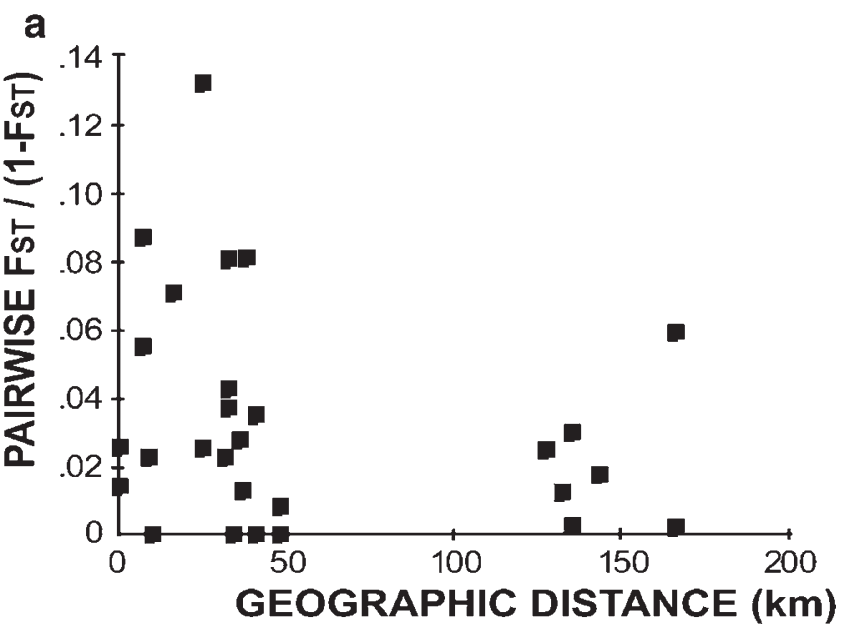

b
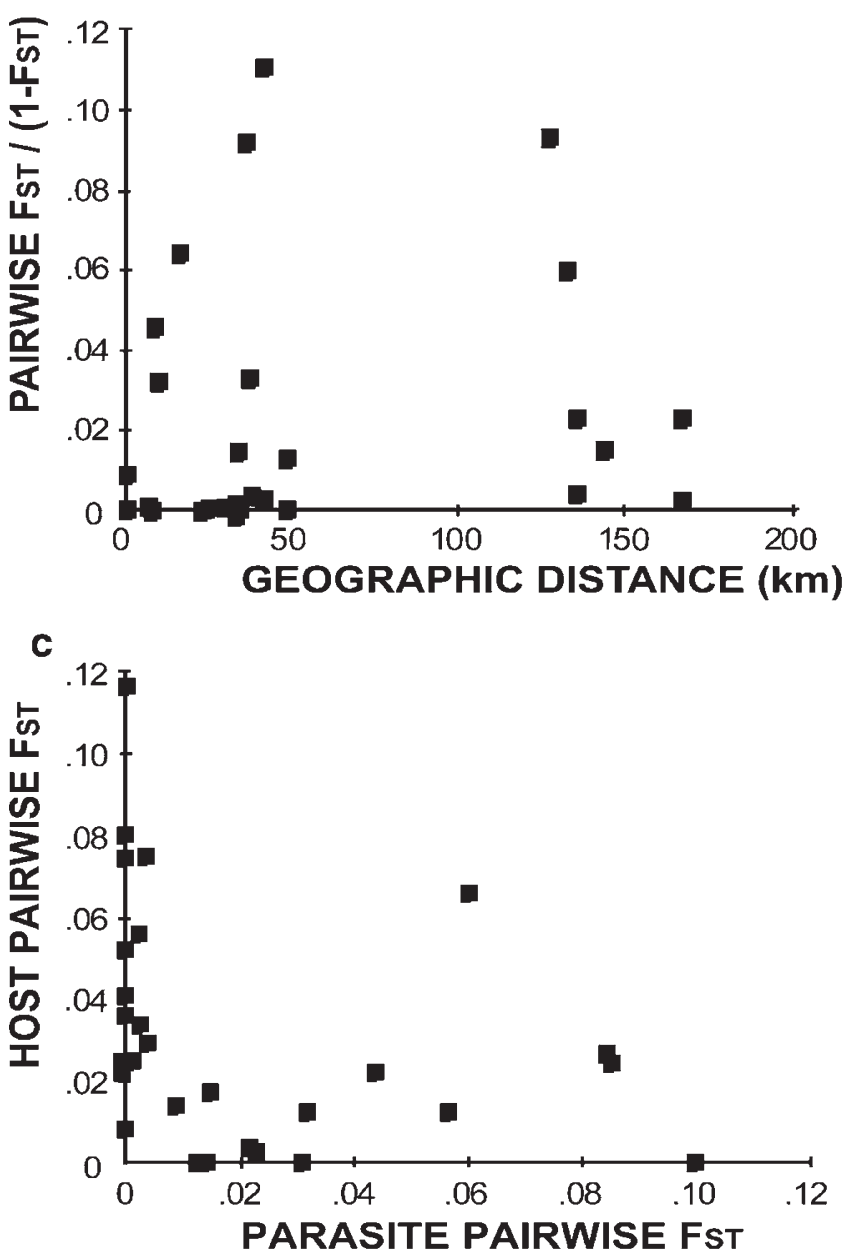

Figure 2 Pairwise $F_{\mathrm{ST}}$ between (a) host and (b) parasite populations in relation to geographic distances between the populations. Pairwise $F_{\mathrm{ST}}$ values were transformed as $F_{\mathrm{ST}} /\left(1-F_{\mathrm{ST}}\right)$. (c) Pairwise $F_{\mathrm{ST}}$ between host populations plotted with the pairwise $F_{\mathrm{ST}}$ between the parasite populations.

lence, and local adaptation, as well as for host resistance occurs in this study system. This suggests that the natural selection imposed by the host on the parasite and vice versa is strong enough to counteract the effects of high gene flow.

\section{Acknowledgements}

We thank Jukka Jokela, Susanna Puustinen, and Veikko Salonen for comments on a previous version of the manuscript. This study was funded by the Academy of Finland.

\section{References}

Bell G (1982). The Masterpiece of Nature: The Evolution and Genetics of Sexuality. University of California Press: Berkeley, CA.

Davies CM, Webster JP, Kruger O, Munatsi A, Ndamba J, Woolhouse MEJ (1999). Host-parasite population genetics: a crosssectional comparison of Bulinus globosus and Schistosoma haematobium. Parasitology 119: 295-302.

Delmotte F, Bucheli E, Shykoff JA (1999). Host and parasite population structure in a natural plant-pathogen system. Heredity 82: 300-308.

Dybdahl M, Lively CM (1996). The geography of coevolution: comparative population structures for a snail and its trematode parasite. Evolution 50: 2264-2275.

Gandon S, Capowiez Y, Dubois Y, Michalakis Y, Olivieri I (1996). Local adaptation and gene-for-gene coevolution in a metapopulation model. Proc R Soc Lond B 263: 1003-1009.

Giles BE, Goudet J (1997). Genetic differentiation in Silene dioica metapopulations: estimation of spatiotemporal effects in a successional plant species. Am Nat 149: 507-526.

Goodnight CJ (1988). Epistasis and the effect of founder events on the additive genetic variance. Evolution 42: 441-445.

Goudet J (1999). FSTAT, a program to estimate and test gene diversities and fixation indices (version 2.8). Updated from Goudet (1995).

Goudet J, Raymond M, De Meeüs T, Rousset F (1996). Testing differentiation in diploid populations. Genetics 144: 1933-1940.

Hamilton WD (1980). Sex versus non-sex versus parasite. Oikos 35: 282-290.

Hamrick J (1989). Isozymes and the analysis of genetic structure in plant populations. In: Soltis D, Soltis P (eds) Isozymes in Plant Biology, Chapman and Hall: London. pp 87-105.

Hamrick J, Godt M (1990). Allozyme diversity in plant species. In: Brown A, Clegg M, Kahlerand A, Weir B (eds) Plant Population Genetics, Breeding, and Genetic Resources, Sinauer Associates: Sunderland, MA. pp 43-63.

Hebert PDN, Beaton MJ (1989). Methodologies for allozyme analysis using cellulose acetate electrophoresis: A practical handbook. Helena Laboratories: Beaumont, TX.

Jaenike J (1978). An hypothesis to account for the maintenance of sex within populations. Evol Theory 3: 191-194.

Kaltz O, Gandon S, Michalakis Y, Shykoff JA (1999). Local maladaptation in the anther-smut fungus Microbotryum violaceum to its host plant Silene latifolia: evidence from a cross-inoculation experiment. Evolution 53: 395-407.

Koskela T (2002). Variation in life-history traits among Urtica dioica populations with different history of parasitism by the holoparasitic plant Cuscuta europaea. Evol Ecol (in press).

Koskela T, Salonen V, Mutikainen P (2000). Local adaptation of a holoparasitic plant, Cuscuta europaea: variation among populations. J Evol Biol 13: 749-755.

Koskela T, Salonen V, Mutikainen P (2001). Interaction of a host plant and its holoparasite: effects of previous selection by the parasite. J Evol Biol 14: 910-917.

Kuijt J (1969). The Biology of Parasitic Flowering Plants. University of California Press: Berkeley, CA.

Lande R, Barrowclough GF (1987). Effective population size, genetic variation, and their use in population management. In: Soulé ME (ed) Viable Populations for Conservation, Cambridge University Press: Cambridge. pp 69-86.

Lively CM (1989). Adaptation by a parasitic trematode to local populations of its snail host. Evolution 43: 1663-1671.

Lively CM (1999). Migration, virulence, and the geographic mosaic of adaptation by parasites. Am Nat 153: S34-47. 
Machado MA, Zetsche K (1990). A structural, functional and molecular analysis of plastids of the holoparasites Cuscuta reflexa and Cuscuta europaea. Planta 181: 91-96.

Mantel N (1967). Detection of disease, clustering and generalized regression approach. Cancer Res 27: 209-220.

Martinez JG, Soler JJ, Soler M, Møller AP, Burke T (1999). Comparative population structure and gene flow of a brood parasite, the great-spotted cuckoo (Clamator glandarius) and its primary host, the magpie (Pica pica). Evolution 53: 269-278.

Michalakis Y, Sheppard AW, Noël V, Olivieri I (1994). Population structure of a herbivorous insect and its host plant on a microgeographical scale. Evolution 47: 1611-1616.

Mulvey M, Aho JM, Lydeard C, Leberg PL, Smith MH (1991). Comparative population genetic structure of a parasite (Fascioloides magna) and its definitive host. Evolution 45: 1628-1640.

Musselman LJ, Press MC (1995). Introduction to parasitic plants. In: Press MC, Graves JD (eds) Parasitic Plants, Chapman \& Hall: London. pp 1-13.

Nadler SA (1995). Microevolution and the genetic structure of parasite populations. J Parasitol 81: 395-403.

Nei M (1987). Molecular Evolutionary Genetics. Columbia University Press: New York.

Parker C, Riches CR (1993). Parasitic Weeds of the World: Biology and Control. CAB International: Wallingford, UK.
Podolsky RH, Holtsford TP (1995). Population structure of morphological traits in Clarkia dudleyana I. Comparison of $\mathrm{F}_{\mathrm{ST}}$ between allozymes and morphological traits. Genetics 140: 733-744.

Press MC, Graves JD, Stewart GR (1990). Physiology of the interaction of angiosperm parasites and their higher plant hosts. Plant, Cell Environm 13: 91-104.

Price PW (1980). Evolutionary Biology of Parasites. Princeton University Press: Princeton, NJ.

Richardson BJ, Bavestock PR, Adams M (1986). Allozyme Electrophoresis. A Handbook for Animal Systematics and Population Studies. Academic Press: New York.

Rousset F, Raymond M (1997). Statistical analyses of population genetic data: new tools, old concepts. Trends Ecol Evol 12: 313-317.

Thompson JN (1994). The Coevolutionary Process. The University of Chicago Press: Chicago.

Whitlock MC, McCauley DE (1990). Some population genetic consequences of colony formation and extinction: genetic correlations within founding groups. Evolution 44: 1717-1724.

Whitlock MC, McCauley DE (1999). Indirect measures of gene flow and migration: $\mathrm{F}_{\mathrm{ST}} \neq 1 /(4 \mathrm{Nm}+1)$. Heredity $82: 117-125$. 